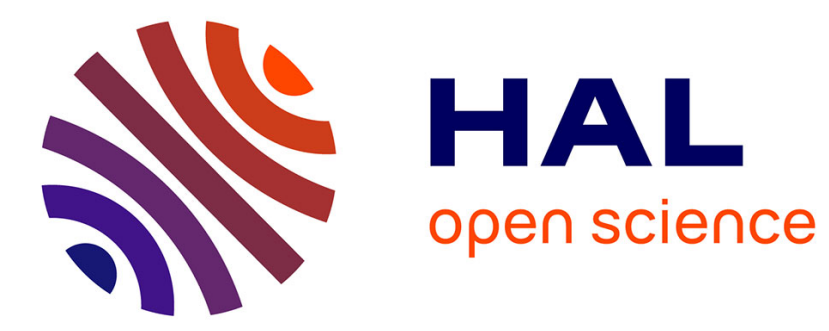

\title{
Millimeter-Scale Hexagonal Boron Nitride Single Crystals for Nanosheet Generation
}

Yangdi Li, Vincent Garnier, Philippe Steyer, Catherine Journet, Bérangère Toury

\section{- To cite this version:}

Yangdi Li, Vincent Garnier, Philippe Steyer, Catherine Journet, Bérangère Toury. Millimeter-Scale Hexagonal Boron Nitride Single Crystals for Nanosheet Generation. ACS Applied Nano Materials, 2020, 3 (2), pp.1508-1515. 10.1021/acsanm.9b02315 . hal-02503025

\section{HAL Id: hal-02503025 \\ https://hal.science/hal-02503025}

Submitted on 13 Apr 2021

HAL is a multi-disciplinary open access archive for the deposit and dissemination of scientific research documents, whether they are published or not. The documents may come from teaching and research institutions in France or abroad, or from public or private research centers.
L'archive ouverte pluridisciplinaire HAL, est destinée au dépôt et à la diffusion de documents scientifiques de niveau recherche, publiés ou non, émanant des établissements d'enseignement et de recherche français ou étrangers, des laboratoires publics ou privés. 


\title{
Millimeter-Scale Hexagonal Boron Nitride Single \\ Crystals for Nanosheet Generation
}

Yangdi Lifł, Vincent Garniert, Philippe Steyert, Catherine Journetł, Bérangère Tourył* *

\$ Laboratoire des Multimatériaux et Interfaces, UMR CNRS 5615, Univ Lyon, Université Claude Bernard Lyon 1, F-69622 Villeurbanne, France

$\dagger$ Laboratoire MATEIS, UMR CNRS 5510, Univ Lyon, INSA Lyon, F-69621Villeurbanne, France

AUTHOR INFORMATION

Corresponding Author

*E-mail: toury@univ-lyon1.fr

KEYWORDS: Boron Nitride, 2D material, Nanosheet, Polymer Derived Ceramics, Sintering

\begin{abstract}
Development of next generation two-dimensional (2D) transistors or photo-electronic devices is closely linked to advances in 2D materials. Due to its outstanding properties (insulating, stable,
\end{abstract}


inert, transparent, isostructural to graphene...), hexagonal boron nitride ( $\mathrm{hBN})$ crystal and in particular its exfoliated nanosheets form, is a choice material to fabricate sensors or plasmonic and photonic devices. However, a wide development of these heterostructures still suffers from a lack of large samples and in ample supply. In this context, we propose the fabrication of large exceptional quality $\mathrm{hBN}$ single crystals of more than few millimeters lateral size by using polymer route combined with a sintering process. The structural quality and compositional purity are retained after exfoliation and dry transfer of these free standing Boron Nitride NanoSheets (BNNSs) onto Si substrates. This developed method can be achieved under short and soft conditions and leads to BNNSs with lateral sizes of several hundreds of microns. This work paves the way for a wide use of BNNS for 2D material applications.

\section{INTRODUCTION}

Produced as nanomaterial, $\mathrm{hBN}$, as an excellent dielectric material, can be suitable for many applications that require BNNSs ranging from one to hundreds of layers. Its atomically flat surface, with no dangling bonds nor charge traps on the surface ${ }^{1}$ make it very interesting as a substrate $^{2-4}$ or encapsulating layer ${ }^{5,6}$ for two-dimensional materials, intercalant in Van der Waals heterostructures, ${ }^{7}$ gate dielectric, ${ }^{8,9}$ counter electrode in dye-sensitized solar cells, ${ }^{10}$ and many others. ${ }^{1}$ hBN also possesses excellent photoelectric properties such as distinct violet or ultraviolet (UV) luminescence emissions, making it all the more attractive for optoelectronic devices, such as deep ultraviolet light emitting devices, ${ }^{11,12}$ UV photoconductive detectors ${ }^{13}$ and single photon emitters. ${ }^{14}$ In this rich applicative context, BNNSs are highly desirable as a building blocks (substrate, intercalant or encapsulating layer) for 2D heterostructures, and 2D- 
$\mathrm{hBN}$ has become among the most sought inorganic 2D material. ${ }^{15}$ However, it is obvious that generating efficient $2 \mathrm{D}$ electronic devices requires from the beginning high quality $\mathrm{hBN}$ substrate displaying crystalline and chemical purity as well as wafer scale size. Up to now, two main strategies to produce BNNSs have been proposed, involving either "bottom-up" or "topdown" approaches. ${ }^{16}$ Bottom-up routes mainly include Chemical Vapor Deposition (CVD) ${ }^{17-19}$ and derivatives (LPCVD, ${ }^{20}$ MOCVD, ${ }^{21,22}$ ), Ion Beam Sputtering Deposition (IBSD) ${ }^{23}$ and Molecular Beam Epitaxy (MBE) ${ }^{24}$. While these bottom-up approaches have the potential for large surface areas, the synthesis of a single-crystal hBN film still remains elusive and let alone high quality transfer at the wafer-scale. ${ }^{25}$ Furthermore, they may be affected by the morphology of the substrate and the reactants purity. ${ }^{26-28}$ Top-down methods rely on mechanical ${ }^{16,29,30}$ or chemical $^{31}$ exfoliation from bulk $\mathrm{hBN}$ crystals that can be either commercial ones or lab-scale samples. A first commercial source ${ }^{32}$ is obtained from an oxygen-containing boron compound reacting with a nitrogen-containing source. These materials exhibit quite small crystalline domains (from sub-micron up to $10 \mu \mathrm{m}$ ) which are not so convenient for exfoliation. Besides, HQ Graphene, ${ }^{33}$ a commercial supplier, claims the production of high quality crystals with a size reaching $1 \mathrm{~mm}$, but there is no real information about the chemical process used to synthesize this material and the exfoliated sheets demonstrate a loss of their lateral size. ${ }^{33,34}$ Beyond commercial ones, samples supplied by NIMS lab are used by most of the research groups over the world. ${ }^{35-37}$ Since they can offer exceptional quality samples with large lateral size which can be almost retained after exfoliation, the fabrication technique is based on severe conditions of pressure and temperature that could limit upscaling or industrial processes. ${ }^{35}$ Still starting from a molten solvent system, Edgar's group is now coming close to achieving the similar quality samples by a simpler and cheaper process. ${ }^{38,39}$ However, they currently have ten times more 
crystal defects, or imperfections, in their structure ${ }^{35}$ and it can be mentioned that the process is a bit long (more than 80 hours). ${ }^{38}$ In our group, we have recently developed a new hBN synthesis approach by combining a polymer route with a sintering process to achieve polycrystalline samples made of more than $200 \mu^{2}$ single crystals. ${ }^{40,41}$ This process deals with softer conditions of pressure and temperature and shorter time but gives samples that do not reach yet the required quality for $2 \mathrm{D}$ devices. In this paper, we will show that, by improving our process in term of sintering conditions and chemistry of the system, we are now able to deliver transparent exceptionally high structural quality boron nitride single crystals of more than $1 \mathrm{~mm}$ in lateral size.

\section{RESULTS AND DISCUSSION}

\section{Material synthesis.}

Polymer Derived Ceramics pathway is known for many years to produce hexagonal boron nitride from borazine precursor. However, this chemical process requires quite high temperatures (more than $1800^{\circ} \mathrm{C}$ ) to get perfectly crystallized $\mathrm{hBN} .{ }^{42}$ In this context, addition of a crystallization promoter $\left(\right.$ like $\left.\mathrm{Li}_{3} \mathrm{~N}\right)$ is now commonly used to enhance cristallinity at lower temperatures. ${ }^{19,43}$ In order to go further in the crystallization rate, our group has previously demonstrated the possibility to use an additivated preceramic polymer in a SPS system. ${ }^{40,41}$ Here, we show how, by tuning the sintering process and the additive content, we can get millimeter-scale $\mathrm{hBN}$ single crystal that can be used to generate BNNSs. Figure 1 illustrates the whole process. Freshly distillated borazine is first polycondensed into a less volatile and thus more processable liquid polyborazilene $(\mathrm{PBN})$. A mixture of $\mathrm{PBN}$ and $35 \mathrm{wt} . \% \mathrm{Li}_{3} \mathrm{~N}$ is then preceramized at $650^{\circ} \mathrm{C}$ under $\mathrm{N}_{2}$ for $1 \mathrm{~h}$ to form the preceramic powder which is placed into a $\mathrm{BN}$ crucible itself introduced 
into a pressure-controlled furnace. Based on preliminary results, optimal sintering conditions have been determined to be a temperature of $1800^{\circ} \mathrm{C}$, a pressure of $180 \mathrm{MPa}$ and a dwelling time of $8 h$.
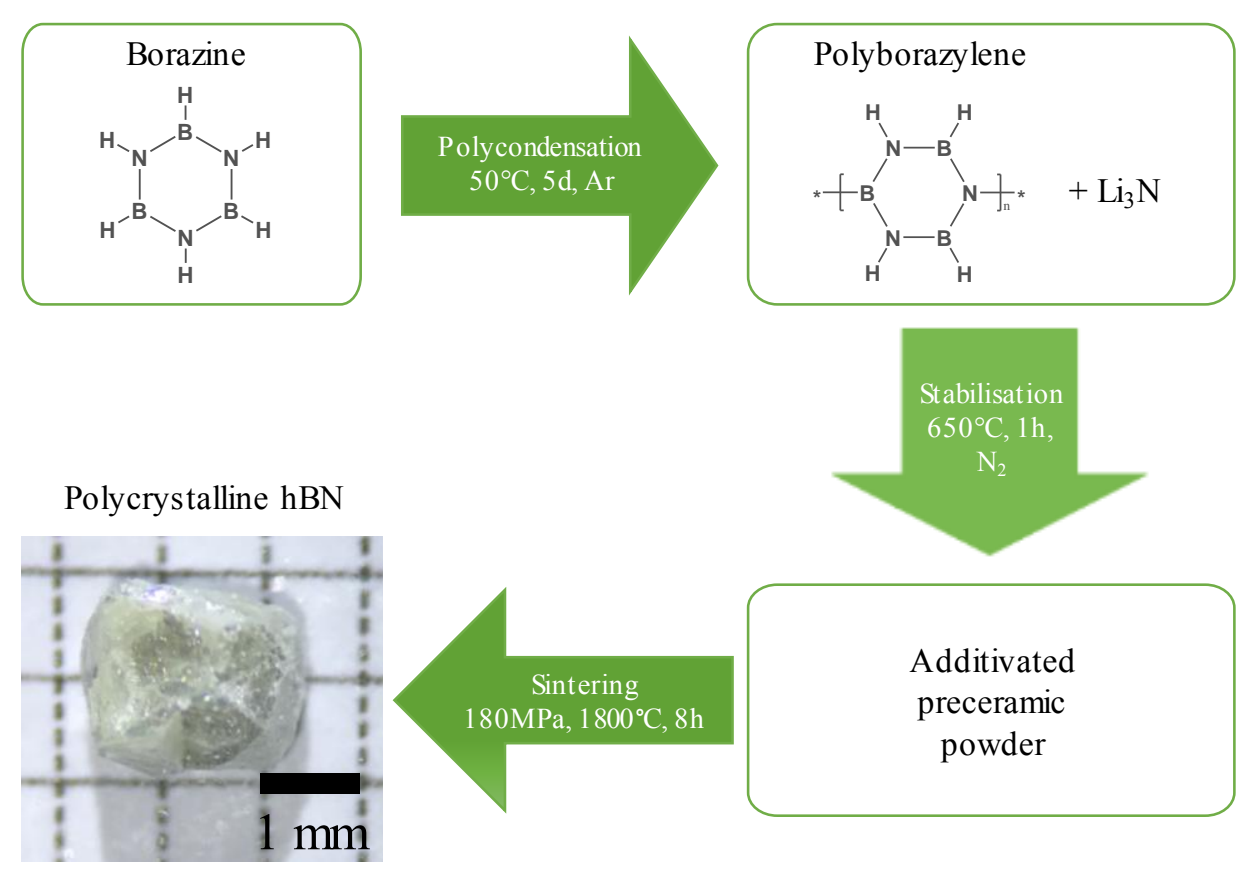

Figure 1. Scheme illustrating the hBN synthesis starting from borazine.

As-obtained bulk material. Naked eyes and optical microscopy observations of the as-sintered sample (Figure 2a and 2b) reveal that it is composed of faceted millimeter-sized regions, which is similar with the domain size of $\sim 1 \mathrm{~mm}$ obtain by Edgar's group ${ }^{38}$ and a bit lower than the few millimeters obtain by NIMS group. ${ }^{36}$ The X-Ray Diffraction (XRD) pattern (Figure 2c) shows only well-separated, thin single peaks that all can be assigned to the crystallographic planes of hBN crystal, as described in the standard JCPDS database (00-034-0421). This demonstrates the perfect structural ordering of the $\mathrm{hBN}$ sample, as confirmed by Raman spectrometry. The Raman spectra were recorded in two frequency shift ranges and exhibit two single peaks (Figure $2 \mathrm{~d}$ and 2e). The low frequency peak at $52.6 \mathrm{~cm}^{-1}$ (FWHM of about $1.2 \mathrm{~cm}^{-1}$ ) corresponds to interlayer 
vibrations, referred to as the interlayer shear mode. ${ }^{44,45}$ The second peak, measured at $1366.0 \mathrm{~cm}^{-}$ ${ }^{1}$, exactly matches the value expected for the in-plane shear mode $\mathrm{E}_{2 \mathrm{~g}}$ symmetry of $\mathrm{hBN}$. $^{29,44} 46,47$ This high frequency peak has a FWHM of about $7.6 \mathrm{~cm}^{-1}$, which is comparable to the best value reported for hBN single crystals obtained by NIMS lab $\left(7.3 \mathrm{~cm}^{-1}\right)$ using the High Pressure High Temperature (HPHT) method ${ }^{36,48}$ and by Edgar's group $\left(7.8 \mathrm{~cm}^{-1}\right)$ using nickel-chromium solvent. ${ }^{38}$ The integrated intensity of the $52.6 \mathrm{~cm}^{-1}$ signal is about a fortieth of the $1366.0 \mathrm{~cm}^{-1}$ one $\left(\mathrm{I}_{\text {low }} / \mathrm{I}_{\text {high }} \approx 1 / 43\right)$, which is consistent with published results. ${ }^{44,45}$ Both optical and Raman analyses fully attest the excellent crystallinity of the produced $\mathrm{hBN}$.
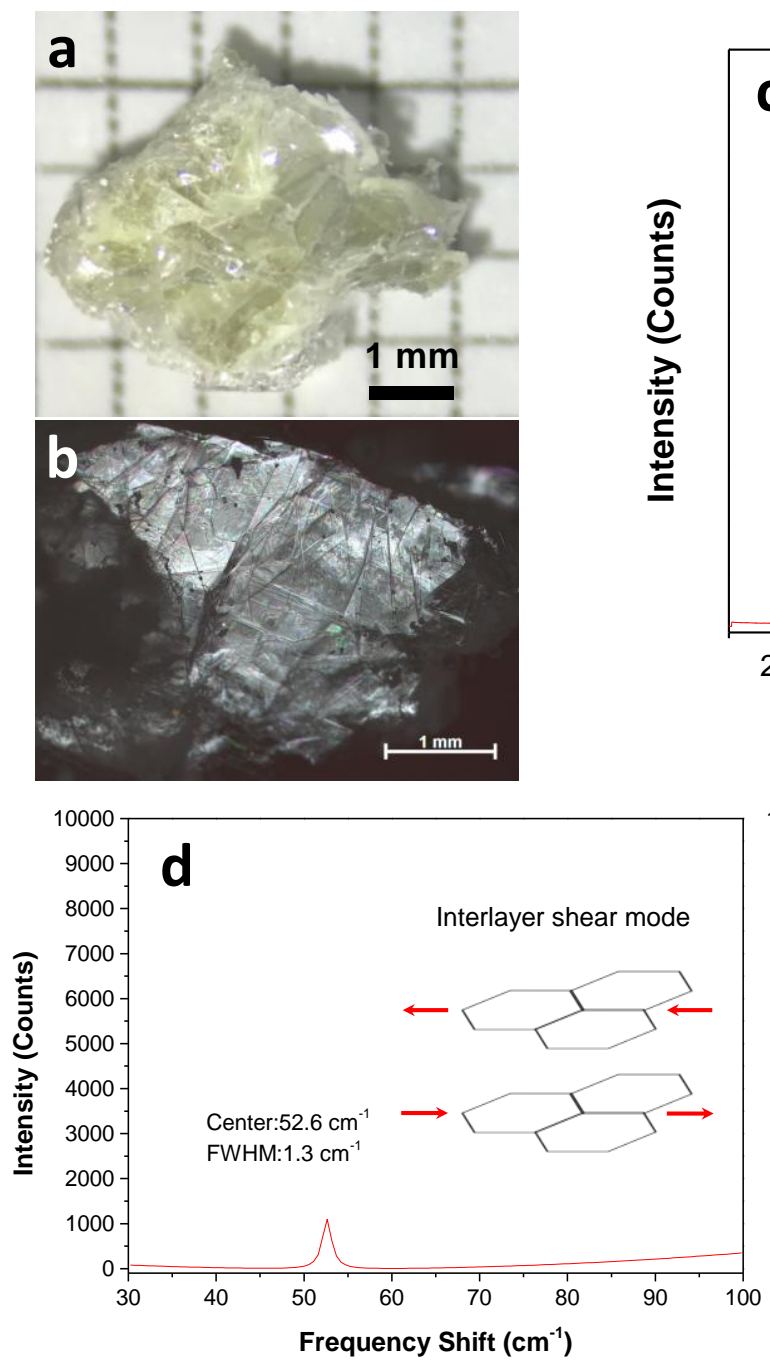
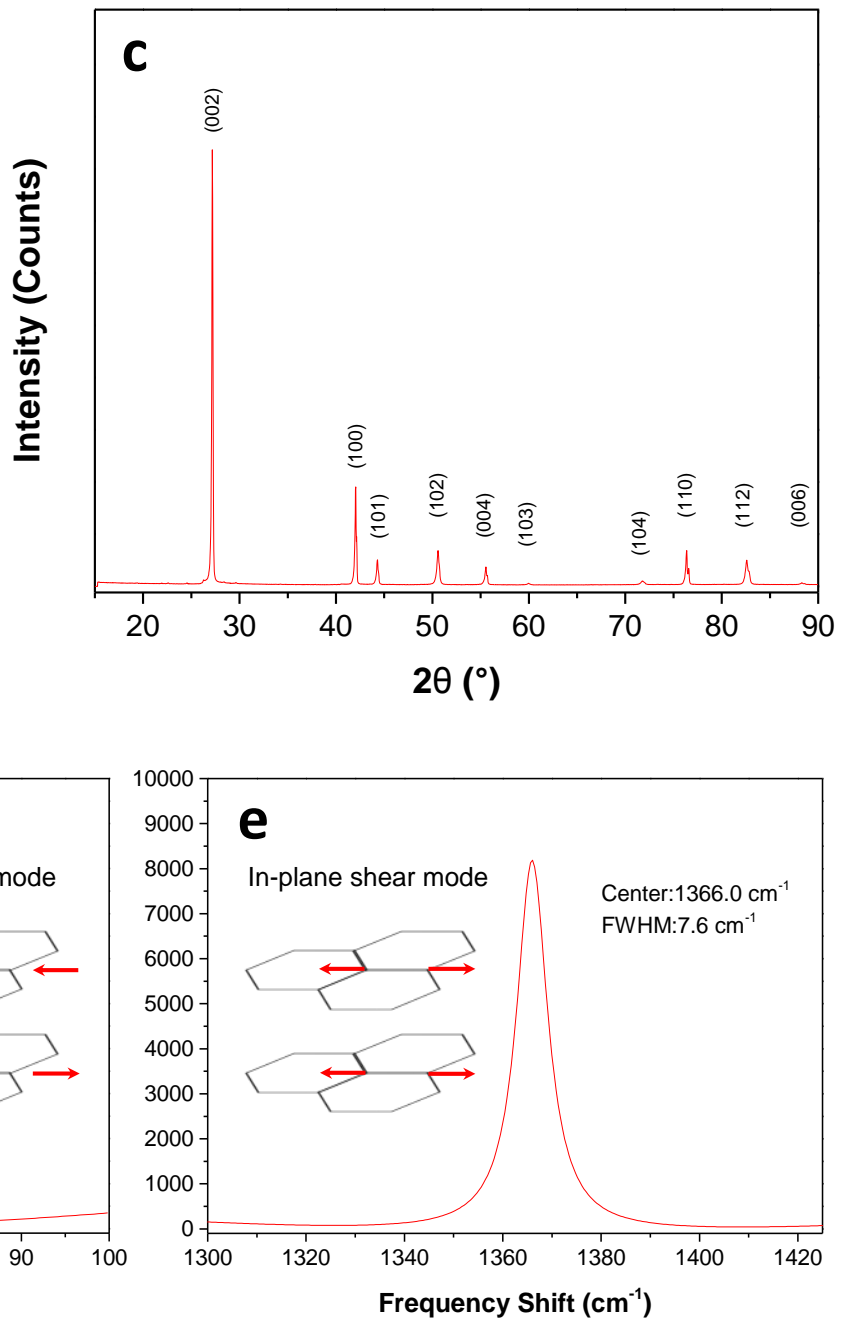
Figure 2. Characterization of the bulk sample, a)- optical image; b)- optical microscopy image; c)- XRD pattern; d, e)- respectively low and high frequency Raman spectra.

Obtaining hBN with such crystalline quality may be explained by using a large amount of $\mathrm{Li}_{3} \mathrm{~N}$ (35 wt.\%) which plays a key role in the liquid-solid sintering mechanism. By comparing with previous studies in which only $5 \mathrm{wt} . \%$ of $\mathrm{Li}_{3} \mathrm{~N}$ was added, ${ }^{40,41}$ the growth mechanism is different. Although the Li based solvent seems to play an important role, the crystal growth process of $\mathrm{hBN}$ does not appear as a simple precipitation from a solution in molten lithium and the hBN crystals rather look like the product of a reaction in the ternary Li-B-N system. In that case, we can assume that the growth occurs in the liquid phase and the proposed crystallization mechanism is based on previous studies reported by Bezrukov ${ }^{49}$ and other groups. ${ }^{50-52}$ At around $600-700{ }^{\circ} \mathrm{C}, \mathrm{Li}_{3} \mathrm{BN}_{2}$ formed by reaction between $\mathrm{Li}_{3} \mathrm{~N}$ and preceramic $\mathrm{BN}$, melts, and infiltrates amorphous BN to dissolve it, leading to highly crystallized hBN. Moreover, it can be noticed that our experiments have been performed in BN-crucibles, which may favor the nucleation of hBN.

hBN freestanding crystals and nanosheets. At the macroscopic scale, the raw material shows evidence for intertwining of large crystals. Freestanding, colorless and transparent hBN crystals of about $2 \mathrm{~mm}$, can be easily extracted from this bulk sample, by simple sliding with tweezers (Figure $3 \mathrm{a}$ and $3 \mathrm{~b}$ ). To further reduce the crystals thickness in the c-axis direction, yet keeping them as large as possible along in-plane dimension, crystals have been exfoliated using a polydimethylsiloxane (PDMS) dry transfer (Figure 3c) and deposited onto an oxidized silicon substrate $\left(285 \mathrm{~nm}\right.$ thick $\left.\mathrm{SiO}_{2}\right)$ (Figure 3d). Such isolated BNNSs present flat and smooth surfaces over distance varying from $100 \mu \mathrm{m}$ to more than $1 \mathrm{~mm}$, that is larger than what is obtained with commercial samples which show a loss of their lateral size after exfoliation. ${ }^{33,34}$ Their 
thicknesses were measured by Atomic Force Microscopy (AFM) (Figure 3e and 3f) and line profiles (Figure 3g) give typical step values of $4-6 \mathrm{~nm}$, corresponding to approximately ten layers.
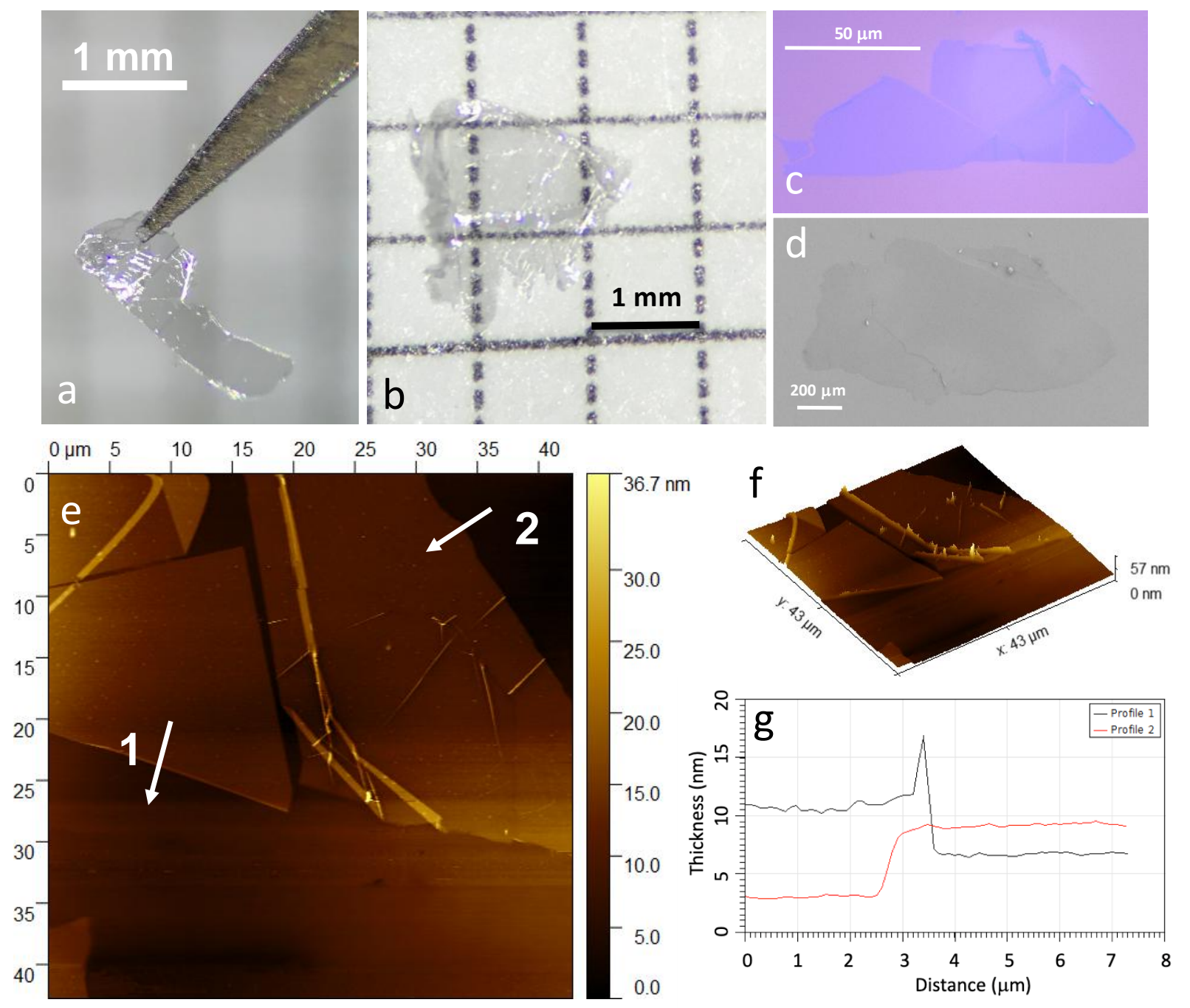

Figure 3. Microstructural characterization of $h B N$ freestanding crystals and nanosheets, $a, b)-$ optical images of freestanding crystals; c)- electron microscopy image of a BNNS transferred onto PDMS; d)- optical micrograph of a BNNS deposited onto $\mathrm{Si} / \mathrm{SiO}_{2}$ substrate; e)- AFM topography image of $\mathrm{hBN}$ nanosheets ; f)- corresponding 3D AFM image and g)- line profiles recorded along arrows 1 and 2 from image e indicating the nanosheets thickness. 
After deposition, the crystalline signature of crystals was confirmed by XRD, and only hBN (002) and (004) peaks are observed (Figure 4a). This results from the perfect planar alignment of the (002) lattice planes onto the silicon supporting substrate. From the (002) line, we deduced an interplanar spacing of $3.328 \AA$, consistent with the JCPDS data file (00-034-0421) for hBN. Further investigations of hBN thin crystals and nanosheets compared the Raman spectra (Figure 4b-d) for areas of different thicknesses, as identified by optical contrast (yellow spot on Figure 4e-g). Each region displays only the expected $\mathrm{hBN} \mathrm{E}_{2 \mathrm{~g}}$ vibration mode around $1365.5 \mathrm{~cm}^{-1}$, with FWHM $\approx 8 \mathrm{~cm}^{-1}$. When decreasing the hBN crystal thickness, the Raman peak intensity decreases, as already described in literature ${ }^{29}$. At the same time, the FWHM increases from 8.1 $\mathrm{cm}^{-1}$ to $8.7 \mathrm{~cm}^{-1}$. Note that the FWHM of the $E_{2 \mathrm{~g}}$ peak is higher here than that observed previously on hBN bulk crystals $\left(7.7 \mathrm{~cm}^{-1}\right)$. This feature has already been reported in the literature and can be attributed to a local strain occurring when nanosheets are transferred onto a substrate. $^{29}$ 

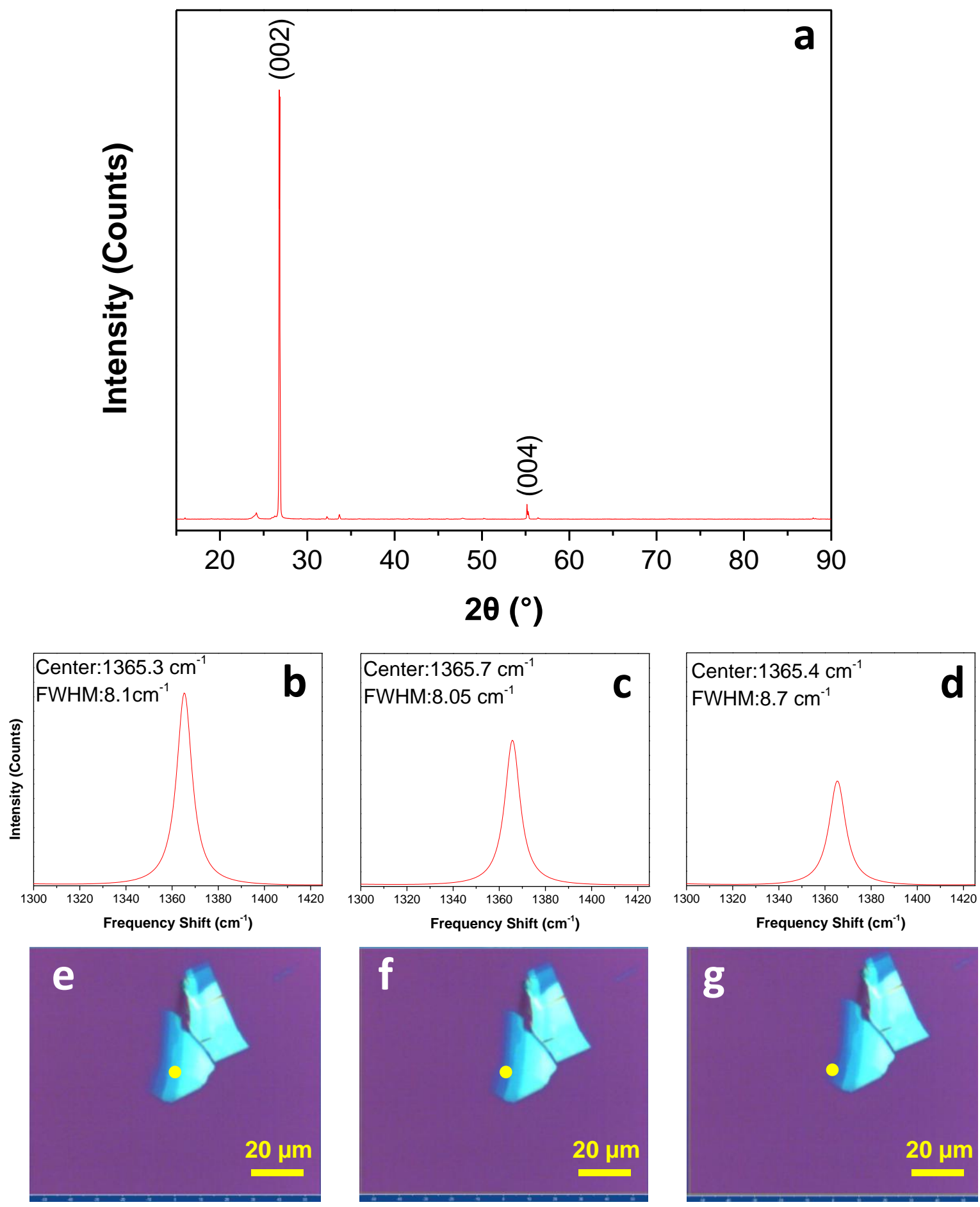

Figure 4. Structural characterizations of $\mathrm{hBN}$ freestanding crystals and BNNSs, a)- XRD pattern of an extracted crystal; b-d)- Raman spectra recorded on a BNNS for different thicknesses and eg)- optical images of the corresponding probed regions (yellow spot). 

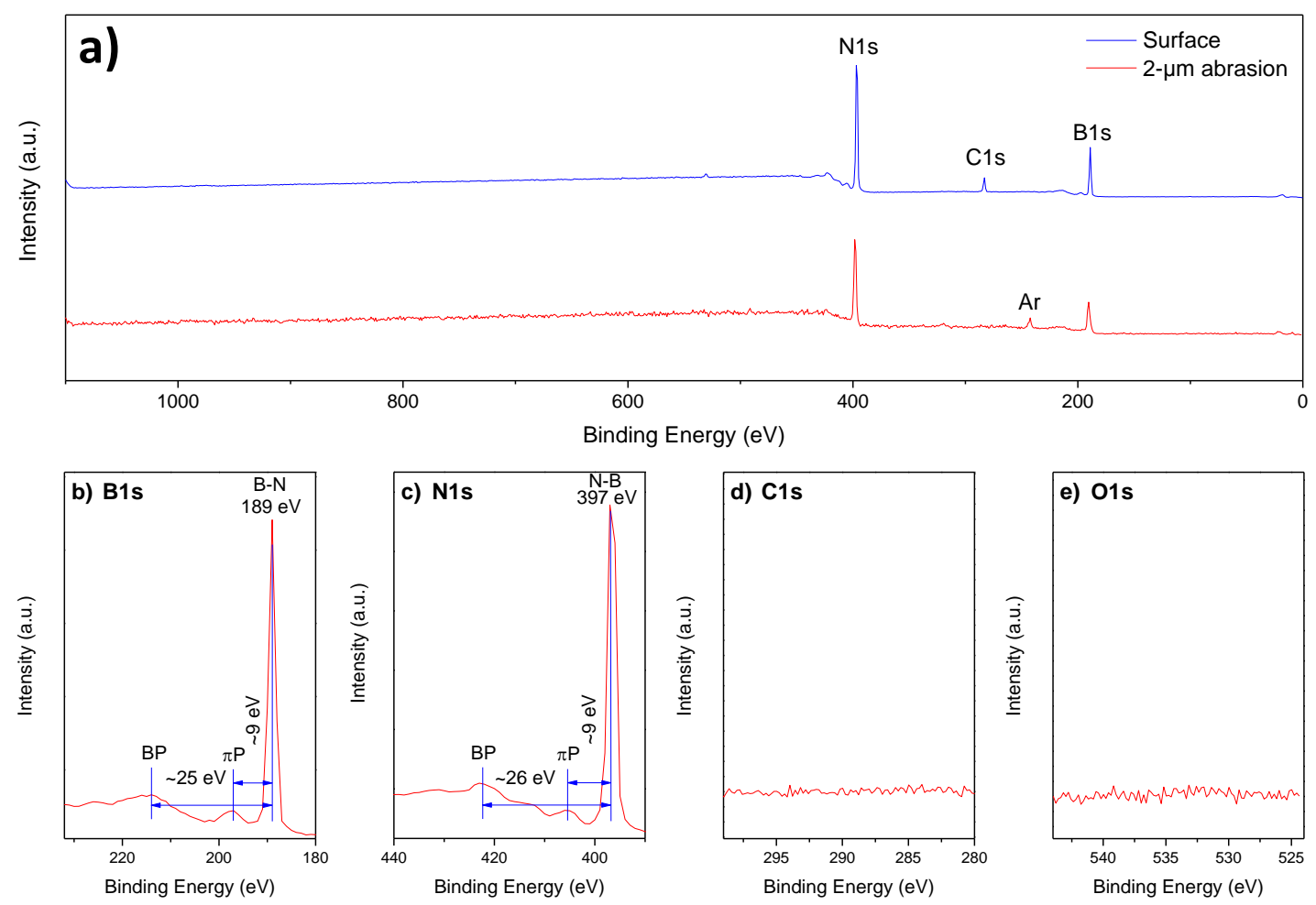

Figure 5. Chemical characterization of hBN single crystal surface, a)- XPS general survey before and after a $2 \mu \mathrm{m}$ surface etching; b)- after etching B1s peak at $189 \mathrm{eV}$, bulk plasmon (BP) loss peak at $\sim 214 \mathrm{eV}$ and $\pi$ plasmon $(\pi \mathrm{P})$ loss peak at $\sim 198 \mathrm{eV}$; c)- after etching N1s peak at $397 \mathrm{eV}$, bulk plasmon loss peak (BP) at $\sim 423 \mathrm{eV}$ and $\pi$ plasmon loss peak $(\pi \mathrm{P})$ at $\sim 406 \mathrm{eV}$ and $\mathrm{d}, \mathrm{e})$ - after etching $\mathrm{C} 1 \mathrm{~s}$ and $\mathrm{O} 1 \mathrm{~s}$ binding energy ranges.

Chemical analyses by X-ray Photoemission Spectroscopy (XPS) were performed on a hBN single crystal before and after a $2 \mu \mathrm{m} \mathrm{Ar}^{+}$etching (Figure 5a). The diameter of the X-ray beam used in these XPS measurements is about $100 \mu \mathrm{m}$, which is smaller than the crystal dimension $\left(\approx 200 \times 200 \mu \mathrm{m}^{2}\right)$. The XPS-B1s $(189 \mathrm{eV}), \mathrm{N} 1 \mathrm{~s}(397 \mathrm{eV}), \mathrm{O} 1 \mathrm{~s}(532 \mathrm{eV})$ and C1s $(283 \mathrm{eV})$ peaks 
are observed on the sample surface, corresponding to an elemental composition of 45.9, 46.2, 0.9 and 7.0 at.\%, respectively, which gives a perfect stoichiometric $\mathrm{B} / \mathrm{N}$ ratio of 0.99 . The $\mathrm{C} 1 \mathrm{~s}$ and O1s peaks are no longer present in the spectrum after etching of the top crystal surface (Figure $5 \mathrm{~d}$ and $5 \mathrm{e}$, respectively), indicating that both are due to surface impurities and that the synthesized sample presents an excellent chemical purity. However, because of the preferential sputtering of nitrogen atoms during the $\mathrm{Ar}^{+}$sputtering process, the $\mathrm{B} / \mathrm{N}$ ratio cannot be used for quantitative composition analysis inside the crystal. Both the B1s and N1s core level spectra (Figure $5 \mathrm{~b}$ and $5 \mathrm{c}$, respectively) show binding energy loss features at $\sim 9$ and $\sim 25 \mathrm{eV}$, respectively, higher than the core peak. These peaks are attributed to $\pi$ plasmons $(\pi \mathrm{P})$ and bulk plasmons (BP), respectively. ${ }^{53}$ These XPS features are used in the literature as the fingerprints of hBN confirming the high quality and purity of hBN single crystals. ${ }^{53-55}$

When deposited on the Transmission Electron Microscopy (TEM) grid, the nanosheet folds onto itself, due to its extremely low thickness (Figure 6a). On a folded well-oriented area, the observed aligned layers allow to determine the interplanar distance of $3.3 \AA$, as expected for hBN (Figure 6b). The Selected Area Electron Diffraction (SAED) pattern recorded on a flat part presents the expected set of six bright diffraction spots with hexagonal symmetry (Figure 6a inset). This demonstrates that the crystal has a single hexagonal structure orientation with a AA' atomic stacking along the c-axis. ${ }^{56}$ This is also confirmed, at higher resolution, by the six hexagonally distributed dots observed on the Fast Fourier Transform (FFT) image obtained from the in-plane atomic arrangement of the nanosheets (Figure 6c, inset). A filtered image, reconstructed from this FFT (Figure 6c), confirms the well-crystallized structure. A $2.5 \AA$ distance between two adjacent atomic columns is deduced (white dots, Figure 6d), which corresponds to the distance between the centers of two neighboring hexagonal rings and 
therefore to the lattice spacing of hBN (Figure 6e). A B-N bond distance of $1.44 \AA$ can then be calculated. This value is consistent with previous results, again attesting to the perfect structural quality of the synthesized hBN.

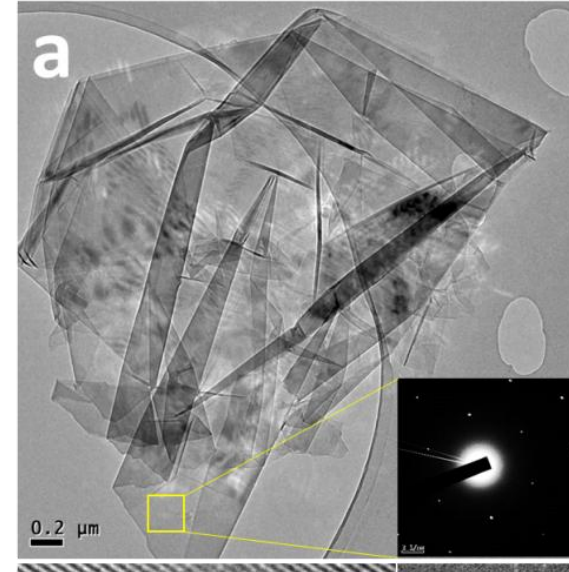

\section{b}
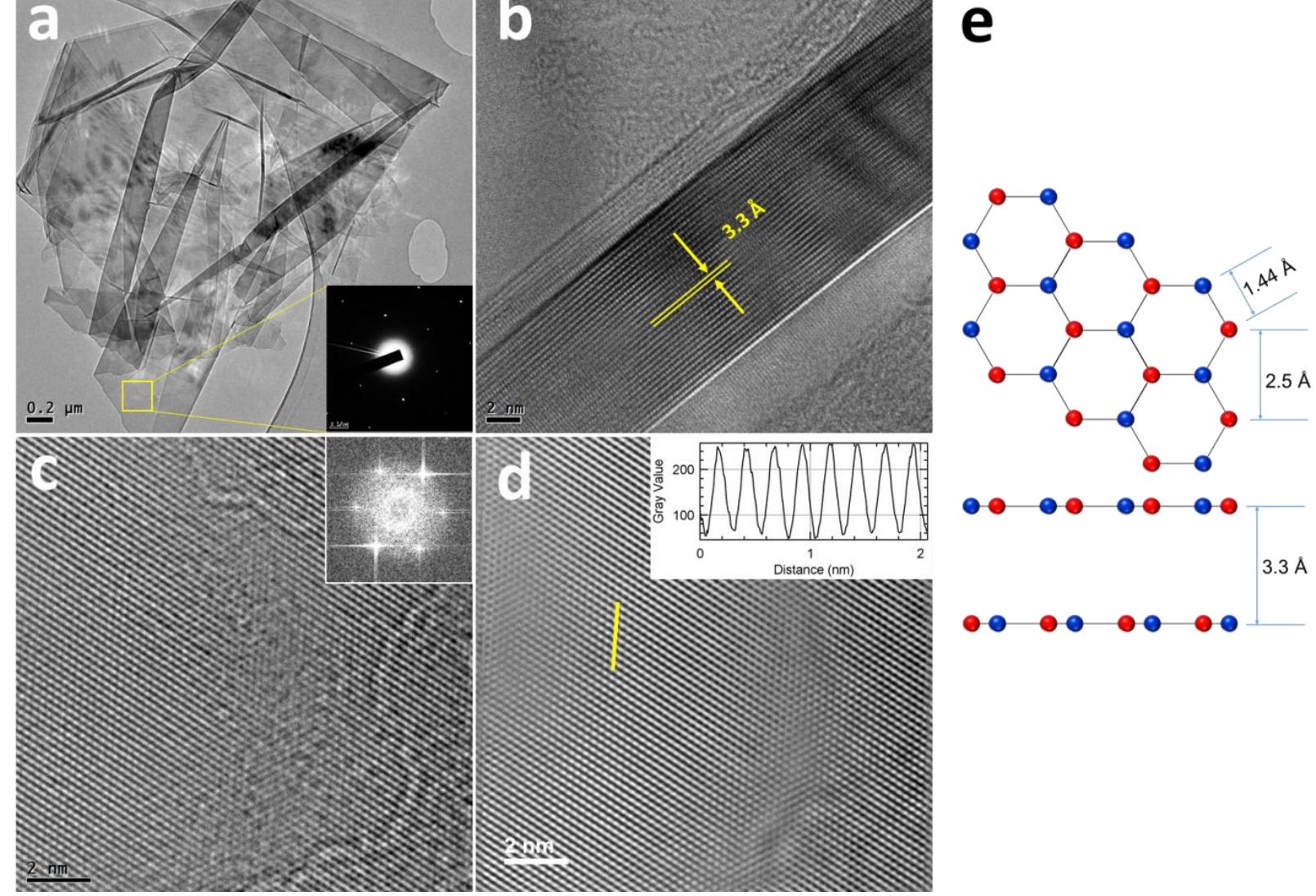

Figure 6. TEM-scale microstructural characterization of BNNSs, a)- BNNS deposited on a holey carbon film, inset : SAED pattern of the selected area ; b)- TEM image of a folded area showing the stacked planes with an interlayer distance of $3.3 \AA$; c)- HRTEM image of the BNNS, inset : corresponding FFT pattern; d)- FFT reconstructed image of c, inset : grey value plot of the yellow line in the image $\mathrm{d}$, allowing to determine distance between two hexagons and e)- $\mathrm{hBN}$ in-plane and inter-plane structures based on HRTEM image measurements. 


\section{CONCLUSION}

In conclusion, a dual process involving a preceramic polymer combined with a sintering step has been used to produce millimeter-sized high purity hBN single crystals. Their perfect chemical and structural quality was shown from the $\mathrm{nm}$ to the $\mathrm{mm}$ scale in the as produced bulk, freestanding crystals and exfoliated nanometer thick sheets. It is worth mentioning that this process is conducted under softer conditions and/or much shorter time than the ones currently used to produce other free standing single crystals. This new synthesis method provides access to an ample supply of large hBN single crystals that can be easily exfoliated into BNNSs for integration in advanced 2D devices.

\section{METHODS}

hBN layers preparation and characterization. Pure borazine is obtained from a reaction between ammonium sulfate $\left[\left(\mathrm{NH}_{4}\right)_{2} \mathrm{SO}_{4}, 99 \%\right.$ purity, Aldrich] and sodium borohydride $\left(\mathrm{NaBH}_{4}\right.$, $98 \%$ purity, Aldrich) in tetraglyme heated to $120{ }^{\circ} \mathrm{C}$ according to a procedure described elsewhere $^{57}$ and purified twice by distillation. The liquid-state polymeric precursor is then obtained by polycondensation of borazine at $50{ }^{\circ} \mathrm{C}$ inside a pressure-sealed system under argon for 5 days, generating colorless polyborazylene $(\mathrm{PBN})$ with a chemical formula $\left(\mathrm{B}_{3.0} \mathrm{~N}_{3.8} \mathrm{H}_{4.0}\right)_{\mathrm{n}}$ as given by elemental analysis. A mixture of liquid $\mathrm{PBN}$ and $35 \mathrm{wt} \%$ lithium nitride $\left(\mathrm{Li}_{3} \mathrm{~N}\right)$ is preceramized at $650^{\circ} \mathrm{C}$ during $1 \mathrm{~h}$ under inert atmosphere of $\mathrm{N}_{2}$. The preceramic powder is then introduced under nitrogen into a $\mathrm{BN}$ crucible and thereafter transferred into a pressure-controlled furnace. The chamber is purged with 3 cycles ( $\mathrm{N}_{2}$ filling followed by pumping) to remove oxygen and moisture. The temperature and the pressure are both increased in 30 minutes up to $1800^{\circ} \mathrm{C}$ and 
up to $180 \mathrm{MPa}$ with $\mathrm{N}_{2}$. The dwelling time is 8 hours before cooling down to room temperature together with pressure release. The material is characterized by optical microscopy, X-ray diffraction (XRD) and Raman spectroscopy using a green laser $(\lambda=532 \mathrm{~nm})$. The material can be quite easily separated from the bulk with tweezers, thereby yielding self-standing crystals. Finally, these crystals are exfoliated using the PDMS dry transfer method and deposited onto $\mathrm{Si} / \mathrm{SiO}_{2}(285 \mathrm{~nm})$ substrates or holey carbon coated copper Transmission Electron Microscopy (TEM) grids. These freestanding thin crystals and nanosheets are characterized as being hBN by optical microscopy, Atomic Force Microscopy (AFM), Scanning Electron Microscopy (SEM), TEM, X-Ray Photoemission Spectroscopy (XPS), XRD and Raman spectroscopy

\section{AUTHOR INFORMATION}

\section{Corresponding Author}

* E-mail: toury@univ-lyon1.fr

\section{ACKNOWLEDGMENT}

This work was financially supported by ANR through the project 14-CE08-0018 «GoBN», European Union Horizon 2020 Program under the Graphene Flagship (grant number 785219), the iMUST LABEX program MUSCAT-2D and Chinese Scholarship Council (CSC). Authors also thank the $\mathrm{CT} \mu$ (Centre Technologique des Microstructures) of the Universite Lyon 1 and the CLYM (Centre Lyonnais de Microscopie) for access to SEM and TEM, CECOMO for access to Raman spectroscopy and Science et Surface (Ecully, France) for XPS analyses. 


\section{REFERENCES}

(1) Wang, J.; Ma, F.; Liang, W.; Sun, M. Electrical Properties and Applications of Graphene, Hexagonal Boron Nitride (h-BN), and Graphene/h-BN Heterostructures. Mater. Today Phys. 2017, 2, 6-34. https://doi.org/10.1016/j.mtphys.2017.07.001.

(2) Dean, C. R.; Young, A. F.; Meric, I.; Lee, C.; Wang, L.; Sorgenfrei, S.; Watanabe, K.; Taniguchi, T.; Kim, P.; Shepard, K. L.; Hone, J. Boron Nitride Substrates for HighQuality Graphene Electronics. Nat. Nanotechnol. 2010, 5 (10), 722-726. https://doi.org/10.1038/nnano.2010.172.

(3) Decker, R.; Wang, Y.; Brar, V. W.; Regan, W.; Tsai, H.-Z.; Wu, Q.; Gannett, W.; Zettl, A.; Crommie, M. F. Local Electronic Properties of Graphene on a BN Substrate via Scanning Tunneling Microscopy. Nano Lett. 2011, 11 (6), 2291-2295. https://doi.org/10.1021/nl2005115.

(4) Jain, N.; Bansal, T.; Durcan, C.; Yu, B. Effect of Substrate on Graphene-Based Interconnects. In 2012 12th IEEE International Conference on Nanotechnology (IEEENANO); IEEE: Birmingham, United Kingdom, 2012; pp 1-4. https://doi.org/10.1109/NANO.2012.6322089.

(5) Gerber, I. C.; Marie, X. Dependence of Band Structure and Exciton Properties of Encapsulated WSe2 Monolayers on the HBN-Layer Thickness. Phys. Rev. B 2018, 98 (24), 245126. https://doi.org/10.1103/PhysRevB.98.245126.

(6) Shautsova, V.; Gilbertson, A. M.; Black, N. C. G.; Maier, S. A.; Cohen, L. F. Hexagonal Boron Nitride Assisted Transfer and Encapsulation of Large Area CVD Graphene. Sci. Rep. 2016, 6 (1), 1-8. https://doi.org/10.1038/srep30210.

(7) Geim, A. K.; Grigorieva, I. V. Van Der Waals Heterostructures. Nature 2013, 499 (7459), 419-425. https://doi.org/10.1038/nature12385.

(8) Britnell, L.; Gorbachev, R. V.; Jalil, R.; Belle, B. D.; Schedin, F.; Katsnelson, M. I.; Eaves, L.; Morozov, S. V.; Mayorov, A. S.; Peres, N. M. R.; Castro Neto, A. H.; Leist, J.; Geim, A. K.; Ponomarenko, L.; Novolselov, K. S. Electron Tunneling through Ultrathin Boron Nitride Crystalline Barriers. Nano Lett. 2012, 12 (3), 1707-1710. https://doi.org/10.1021/nl3002205.

(9) Kim, K. K.; Hsu, A.; Jia, X.; Kim, S. M.; Shi, Y.; Dresselhaus, M.; Palacios, T.; Kong, J. Synthesis and Characterization of Hexagonal Boron Nitride Film as a Dielectric Layer for Graphene Devices. ACS Nano 2012, 6 (10), 8583-8590. https://doi.org/10.1021/nn301675f.

(10) Xu, S. J.; Luo, Y. F.; Zhong, W.; Xiao, Z. H.; Liu, X. Y. Investigation of Hexagonal Boron Nitride for Application as Counter Electrode in Dye-Sensitized Solar Cells. Adv. Mater. Res. 2012, 512-515, 242-245. https://doi.org/10.4028/www.scientific.net/AMR.512-515.242.

(11) Vuong, T. Q. P.; Cassabois, G.; Valvin, P.; Rousseau, E.; Summerfield, A.; Mellor, C. J.; Cho, Y.; Cheng, T. S.; Albar, J. D.; Eaves, L.; Foxon, C. T.; Beton, P. H.; Novikov, S. V.; Gil, B. Deep Ultraviolet Emission in Hexagonal Boron Nitride Grown by HighTemperature Molecular Beam Epitaxy. 2D Mater. 2017, 4 (2), 021023. https://doi.org/10.1088/2053-1583/aa604a. 
(12) Jiang, H. X.; Lin, J. Y. Hexagonal Boron Nitride for Deep Ultraviolet Photonic Devices. Semicond. Sci. Technol. 2014, 29 (8), 084003. https://doi.org/10.1088/02681242/29/8/084003.

(13) Aldalbahi, A.; Feng, P. Development of 2-D Boron Nitride Nanosheets UV Photoconductive Detectors. IEEE Trans. Electron Devices 2015, 62 (6), 1885-1890. https://doi.org/10.1109/TED.2015.2423253.

(14) Xu, Z.-Q.; Elbadawi, C.; Tran, T. T.; Kianinia, M.; Li, X.; Liu, D.; Hoffman, T. B.; Nguyen, M.; Kim, S.; Edgar, J. H.; Wu, X.; Song, L.; Ali, S.; Ford, M.; Toth, M.; Aharonovich, I. Single Photon Emission from Plasma Treated 2D Hexagonal Boron Nitride. Nanoscale 2018, 10 (17), 7957-7965. https://doi.org/10.1039/C7NR08222C.

(15) Wang, J.; Ma, F.; Sun, M. Graphene, Hexagonal Boron Nitride, and Their Heterostructures: Properties and Applications. RSC Adv. 2017, 7 (27), 16801-16822. https://doi.org/10.1039/C7RA00260B.

(16) Zhang, K.; Feng, Y.; Wang, F.; Yang, Z.; Wang, J. Two Dimensional Hexagonal Boron Nitride (2D-HBN): Synthesis, Properties and Applications. J. Mater. Chem. C 2017, 5 (46), 11992-12022. https://doi.org/10.1039/C7TC04300G.

(17) Khan, M. H.; Liu, H. K.; Sun, X.; Yamauchi, Y.; Bando, Y.; Golberg, D.; Huang, Z. FewAtomic-Layered Hexagonal Boron Nitride: CVD Growth, Characterization, and Applications. Mater. Today 2017, 20 (10), 611-628. https://doi.org/10.1016/j.mattod.2017.04.027.

(18) Lee, J. S.; Choi, S. H.; Yun, S. J.; Kim, Y. I.; Boandoh, S.; Park, J.-H.; Shin, B. G.; Ko, H.; Lee, S. H.; Kim, Y.-M.; Lee, Y. H.; Kim, K. K.; Kim, S. M. Wafer-Scale SingleCrystal Hexagonal Boron Nitride Film via Self-Collimated Grain Formation. Science 2018, 362 (6416), 817-821. https://doi.org/10.1126/science.aau2132.

(19) Lu, G.; Wu, T.; Yuan, Q.; Wang, H.; Wang, H.; Ding, F.; Xie, X.; Jiang, M. Synthesis of Large Single-Crystal Hexagonal Boron Nitride Grains on $\mathrm{Cu}-\mathrm{Ni}$ Alloy. Nat Commun 2015, 6 .

(20) Park, J.-H.; Park, J. C.; Yun, S. J.; Kim, H.; Luong, D. H.; Kim, S. M.; Choi, S. H.; Yang, W.; Kong, J.; Kim, K. K.; Lee, Y. H. Large-Area Monolayer Hexagonal Boron Nitride on Pt Foil. ACS Nano 2014, 8 (8), 8520-8528. https://doi.org/10.1021/nn503140y.

(21) Siegel, G.; Gryzbowcki, G.; Hilton, A.; Muratore, C.; Snure, M. Growth of Multi-Layer HBN on Ni(111) Substrates via MOCVD. Crystals 2019, 9 (7), 339. https://doi.org/10.3390/cryst9070339.

(22) Rice, A.; Allerman, A.; Crawford, M.; Beechem, T.; Ohta, T.; Spataru, C.; Figiel, J.; Smith, M. Effects of Deposition Temperature and Ammonia Flow on Metal-Organic Chemical Vapor Deposition of Hexagonal Boron Nitride. J. Cryst. Growth 2018, 485, 90 95. https://doi.org/10.1016/j.jcrysgro.2017.12.011.

(23) Meng, J.; Zhang, X.; Wang, Y.; Yin, Z.; Liu, H.; Xia, J.; Wang, H.; You, J.; Jin, P.; Wang, D.; Meng, X. M. Aligned Growth of Millimeter-Size Hexagonal Boron Nitride SingleCrystal Domains on Epitaxial Nickel Thin Film. Small 2017, 13 (18), 1604179. https://doi.org/10.1002/smll.201604179.

(24) Xu, Z.; Tian, H.; Khanaki, A.; Zheng, R.; Suja, M.; Liu, J. Large-Area Growth of MultiLayer Hexagonal Boron Nitride on Polished Cobalt Foils by Plasma-Assisted Molecular Beam Epitaxy. Sci. Rep. 2017, 7 (1), 1-7. https://doi.org/10.1038/srep43100.

(25) Wu, C.; Soomro, A. M.; Sun, F.; Wang, H.; Huang, Y.; Wu, J.; Liu, C.; Yang, X.; Gao, N.; Chen, X.; Kang, J.; Cai, D. Large-Roll Growth of 25-Inch Hexagonal BN Monolayer 
Film for Self-Release Buffer Layer of Free-Standing GaN Wafer. Sci. Rep. 2016, 6 (1), $1-$ 9. https://doi.org/10.1038/srep34766.

(26) Wang, H.; Zhao, Y.; Xie, Y.; Ma, X.; Zhang, X. Recent Progress in Synthesis of TwoDimensional Hexagonal Boron Nitride. J. Semicond. 2017, 38 (3), 031003. https://doi.org/10.1088/1674-4926/38/3/031003.

(27) Kim, G.; Jang, A.-R.; Jeong, H. Y.; Lee, Z.; Kang, D. J.; Shin, H. S. Growth of HighCrystalline, Single-Layer Hexagonal Boron Nitride on Recyclable Platinum Foil. Nano Lett. 2013, 13 (4), 1834-1839. https://doi.org/10.1021/n1400559s.

(28) Bayer, B. C.; Caneva, S.; Pennycook, T. J.; Kotakoski, J.; Mangler, C.; Hofmann, S.; Meyer, J. C. Introducing Overlapping Grain Boundaries in Chemical Vapor Deposited Hexagonal Boron Nitride Monolayer Films. ACS Nano 2017, 11 (5), 4521-4527. https://doi.org/10.1021/acsnano.6b08315.

(29) Gorbachev, R. V.; Riaz, I.; Nair, R. R.; Jalil, R.; Britnell, L.; Belle, B. D.; Hill, E. W.; Novoselov, K. S.; Watanabe, K.; Taniguchi, T.; Geim, A. K.; Blake, P. Hunting for Monolayer Boron Nitride: Optical and Raman Signatures. Small 2011, 7 (4), 465-468. https://doi.org/10.1002/smll.201001628.

(30) Novoselov, K. S.; Jiang, D.; Schedin, F.; Booth, T. J.; Khotkevich, V. V.; Morozov, S. V.; Geim, A. K. Two-Dimensional Atomic Crystals. Proc. Natl. Acad. Sci. U. S. A. 2005, 102 (30), 10451-10453.

(31) Coleman, J. N.; Lotya, M.; O’Neill, A.; Bergin, S. D.; King, P. J.; Khan, U.; Young, K.; Gaucher, A.; De, S.; Smith, R. J.; Shvets, I. V.; Arora, S. K.; Stanton, G.; Kim H.-Y.; Lee, K.; Kim, G. T.; Duesberg, G. S.; Hallam, T.; Boland, J. J.; Wang, J. J.; Donegan, J. F.; Grunlan, J. C.; Moriarty, G.; Shmeliov, A.; Nicholls, R. J.; Perkins, J. M.; Grieveson, E. M.; Theuwissen, K.; McComb, D. W.; Nellist, P. D.; Nicolosi, V. Two-Dimensional Nanosheets Produced by Liquid Exfoliation of Layered Materials. Science 2011, 331 (6017), 568-571. https://doi.org/10.1126/science.1194975.

(32) Clere, T. M. Method for Making High Thermal Diffusivity Boron Nitride Powders; Google Patents, 2007.

(33) h-BN - Hexagonal Boron Nitride http://www.hqgraphene.com/h-BN.php (accessed Feb 11, 2019).

(34) Zomer, P. J.; Guimarães, M. H. D.; Brant, J. C.; Tombros, N.; van Wees, B. J. Fast Pick up Technique for High Quality Heterostructures of Bilayer Graphene and Hexagonal Boron Nitride. Appl. Phys. Lett. 2014, 105 (1), 013101. https://doi.org/10.1063/1.4886096.

(35) Zastrow, M. Meet the Crystal Growers Who Sparked a Revolution in Graphene Electronics. Nature 2019, 572 (7770), 429-432. https://doi.org/10.1038/d41586-01902472-0.

(36) Taniguchi, T.; Watanabe, K. Synthesis of High-Purity Boron Nitride Single Crystals under High Pressure by Using Ba-BN Solvent. J. Cryst. Growth 2007, 303 (2), 525-529. https://doi.org/10.1016/j.jcrysgro.2006.12.061.

(37) Watanabe, K.; Taniguchi, T.; Kanda, H. Direct-Bandgap Properties and Evidence for Ultraviolet Lasing of Hexagonal Boron Nitride Single Crystal. Nat. Mater. 2004, 3 (6), 404-409. https://doi.org/10.1038/nmat1134.

(38) Liu, S.; He, R.; Xue, L.; Li, J.; Liu, B.; Edgar, J. H. Single Crystal Growth of MillimeterSized Monoisotopic Hexagonal Boron Nitride. Chem. Mater. 2018, 30 (18), 6222-6225. https://doi.org/10.1021/acs.chemmater.8b02589. 
(39) Edgar, J. H.; Hoffman, T. B.; Clubine, B.; Currie, M.; Du, X. Z.; Lin, J. Y.; Jiang, H. X. Characterization of Bulk Hexagonal Boron Nitride Single Crystals Grown by the Metal Flux Technique. J. Cryst. Growth 2014, 403, 110-113. https://doi.org/10.1016/j.jcrysgro.2014.06.006.

(40) Yuan, S.; Linas, S.; Journet, C.; Steyer, P.; Garnier, V.; Bonnefont, G.; Brioude, A.; Toury, B. Pure \& Crystallized 2D Boron Nitride Sheets Synthesized via a Novel Process Coupling Both PDCs and SPS Methods. Sci. Rep. 2016, 6, 20388. https://doi.org/10.1038/srep20388.

(41) Li, Y.; Garnier, V.; Journet, C.; Barjon, J.; Loiseau, A.; Stenger, I.; Plaud, A.; Toury, B.; Steyer, P. Advanced Synthesis of Highly Crystallized Hexagonal Boron Nitride by Coupling Polymer-Derived Ceramics and Spark Plasma Sintering Processes-Influence of the Crystallization Promoter and Sintering Temperature. Nanotechnology 2018, 30 (3), 035604. https://doi.org/10.1088/1361-6528/aaebb4.

(42) Bernard, S.; Miele, P. Polymer-Derived Boron Nitride: A Review on the Chemistry, Shaping and Ceramic Conversion of Borazine Derivatives. Materials 2014, 7 (11), 74367459. https://doi.org/10.3390/ma7117436.

(43) Wang, M.; Kim, M.; Odkhuu, D.; Park, N.; Lee, J.; Jang, W.-J.; Kahng, S.-J.; Ruoff, R. S.; Song, Y. J.; Lee, S. Catalytic Transparency of Hexagonal Boron Nitride on Copper for Chemical Vapor Deposition Growth of Large-Area and High-Quality Graphene. ACS Nano 2014, 8 (6), 5478-5483. https://doi.org/10.1021/nn501837c.

(44) Kuzuba, T.; Era, K.; Ishii, T.; Sato, T. A Low Frequency Raman-Active Vibration of Hexagonal Boron Nitride. Solid State Commun. 1978, 25 (11), 863-865. https://doi.org/10.1016/0038-1098(78)90288-0.

(45) Stenger, I.; Schué, L.; Boukhicha, M.; Berini, B.; Plaçais, B.; Loiseau, A.; Barjon, J. Low Frequency Raman Spectroscopy of Few-Atomic-Layer Thick HBN Crystals. 2D Mater. 2017, 4 (3), 031003. https://doi.org/10.1088/2053-1583/aa77d4.

(46) Reich, S.; Ferrari, A. C.; Arenal, R.; Loiseau, A.; Bello, I.; Robertson, J. Resonant Raman Scattering in Cubic and Hexagonal Boron Nitride. Phys. Rev. B 2005, 71 (20), 205201. https://doi.org/10.1103/PhysRevB.71.205201.

(47) Geick, R.; Perry, C. H.; Rupprecht, G. Normal Modes in Hexagonal Boron Nitride. Phys. Rev. 1966, 146 (2), 543-547. https://doi.org/10.1103/PhysRev.146.543.

(48) Schué, L.; Stenger, I.; Fossard, F.; Loiseau, A.; Barjon, J. Characterization Methods Dedicated to Nanometer-Thick HBN Layers. 2D Mater. 2016, 4 (1), 015028. https://doi.org/10.1088/2053-1583/4/1/015028.

(49) Bezrukov, G.; Butuzov, V.; Nikitina, T.; Feldgun, L.; Filonenk, N.; Khatelis, G. On Crystallization of Cubic Boron Nitride and of Synthetic Diamond. Dokl. Akad. Nauk Sssr 1968, 179 (6), 1326-.

(50) Yamane, H.; Kikkawa, S.; Koizumi, M. High-and Low-Temperature Phases of Lithium Boron Nitride, Li 3 BN 2: Preparation, Phase Relation, Crystal Structure, and Ionic Conductivity. J. Solid State Chem. 1987, 71 (1), 1-11.

(51) Li, S.; Guo, X.; Xu, B.; Wang, H. Fracture Morphology and XRD Layered Characterization of CBN Cake. J Synth Cryst 2012, 41, 15-19.

(52) Xu, B.; Lv, M.-Z.; Yang, H.-M.; Wen, Z.-X. Thermodynamic Analysis of the V-Shaped Area of High Pressure and High Temperature in Cubic Boron Nitride Synthesis with Li3N as a Catalyst. Entropy 2014, 16 (2), 912-920. 
(53) Trehan, R.; Lifshitz, Y.; Rabalais, J. W. Auger and X- ray Electron Spectroscopy Studies of $h \mathrm{BN}, c \mathrm{BN}$, and $\mathrm{N}^{+}{ }_{2}$ Ion Irradiation of Boron and Boron Nitride. J. Vac. Sci. Technol. Vac. Surf. Films 1990, 8 (6), 4026-4032. https://doi.org/10.1116/1.576471.

(54) Weissmantel, C. 4 - Preparation, Structure, and Properties of Hard Coatings on the Basis of i-c and i-Bn. In Thin Films from Free Atoms and Particles; Klabunde, K. J., Ed.; Academic Press, 1985; pp 153-201. https://doi.org/10.1016/B978-0-12-410755-7.500105.

(55) Barton, A. T.; Yue, R.; Anwar, S.; Zhu, H.; Peng, X.; McDonnell, S.; Lu, N.; Addou, R.; Colombo, L.; Kim, M. J.; Wallace, R. M.; Hinkle, C. L.; Transition Metal Dichalcogenide and Hexagonal Boron Nitride Heterostructures Grown by Molecular Beam Epitaxy. Microelectron. Eng. 2015, 147, 306-309. https://doi.org/10.1016/j.mee.2015.04.105.

(56) Yuan, S.; Journet, C.; Linas, S.; Garnier, V.; Steyer, P.; Benayoun, S.; Brioude, A.; Toury, B. How to Increase the H-BN Crystallinity of Microfilms and Self-Standing Nanosheets: A Review of the Different Strategies Using the PDCs Route. Crystals 2016, 6 (5), 55. https://doi.org/10.3390/cryst6050055.

(57) Wideman, T.; Sneddon, L. G. Convenient Procedures for the Laboratory Preparation of Borazine. Inorg. Chem. 1995, 34 (4), 1002-1003. 


\section{For Table of Contents Only :}

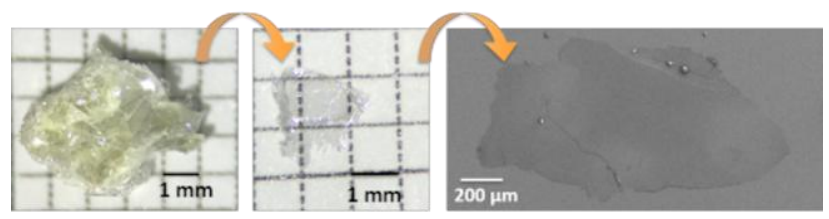

From hexagonal boron nitride crystals to nanosheets 